\title{
Laboratory Test Subcategory
}

National Cancer Institute

\section{Source}

National Cancer Institute. Laboratory Test Subcategory. NCI Thesaurus. Code C83142.

A sub-division of the laboratory test classification. 